\section{Auditory brainstem evoked responses and temperature monitoring during pediatric car- diopulmonary bypass}

Purpose: To examine the effects of temperature on auditory brainstem responses (ABRs) in infants during hypothermic cardiopulmonary bypass for total circulatory arrest (TCA). The relationship between ABRs (as a surrogate measure of corebrain temperature) and body temperature as measured at several temperature monitoring sites was determined.

Methods: In a prospective, observational study, ABRs were recorded non-invasively at normothermia and at every 1 or $2{ }^{\circ} \mathrm{C}$ change in ear-canal temperature during cooling and rewarming in 15 infants (ages: 2 days to 14 months) that required TCA. The ABR latencies and amplitudes and the lowest temperatures at which an ABR was identified (the threshold) were measured during both cooling and rewarming. Temperatures from four standard temperature monitoring sites were simultaneously recorded.

Results: The latencies of ABRs increased and amplitudes decreased with cooling $(P<0.0 \mathrm{I})$, but rewarming reversed these effects. The ABR threshold temperature as related to each monitoring site (ear-canal, nasopharynx, esophagus and bladder) was respectively determined as $23 \pm 2.2^{\circ} \mathrm{C}, 20.8 \pm 1.7^{\circ} \mathrm{C}, 14.6^{\circ} \pm 3.4^{\circ} \mathrm{C}$, and $21.5^{\circ} \pm 3.8^{\circ} \mathrm{C}$ during cooling and $21.8 \pm 1.6^{\circ} \mathrm{C}, 22.4 \pm 2.0^{\circ} \mathrm{C}, 27.6 \pm 3.6^{\circ} \mathrm{C}$ and $23.0 \pm 2.4^{\circ} \mathrm{C}$ during rewarming. The rewarming latencies were shorter and $\mathrm{Q}_{10}$ latencies smaller than the corresponding cooling values $(P<0.01)$. Esophageal and bladder sites were more susceptible to temperature variations as compared with the ear-canal and nasopharynx.

Conclusion: No temperature site reliably predicted an electrophysiological threshold. A faster latency recovery during rewarming suggests that body temperature monitoring underestimates the effects of rewarming in the core-brain. ABRs may be helpful to monitor the effects of cooling and rewarming on the core-brain during pediatric cardiopulmonary bypass.

Objectif : Examiner les effets de la température sur les réponses du tronc cérébral à des stimuli auditifs chez des enfants pendant la circulation extracorporelle hypothermique dans le cas d'un arrêt circulatoire total (ACT). La relation entre les réponses du tronc cérébral (en tant que mesure substitutive de la température cérébrale centrale) et la température du corps (mesurée à différents points d'enregistrement) a été déterminée.

Méthode : Lors d'une étude prospective d'observation, on a enregistré les réponses du tronc cérébral à des stimuli auditifs, de manière non effractive, à la température normale et à chaque changement de température de 1 ou $2^{\circ} \mathrm{C}$ du canal auditif pendant le refroidissement et le réchauffement de 15 enfants (âgés de 2 jours à 14 mois) qui ont eu besoin d'ACT. Les temps de latence et les amplitudes des réponses aux températures les plus basses auxquelles une réponse a été perçue (le seuil) ont été mesurés pendant le refroidissement et le réchauffement. Les températures de quatre points d'enregistrement standards ont été notées simultanément.

Résultats : Les temps de latence des réponses ont augmenté et les amplitudes ont diminué pendant le refroidissement $(P$ $<0,01$ ), mais le réchauffement a renversé ces effets. La température du seuil de réponse au canal auditif, au nasopharynx, à l'oesophage et à la vessie a été respectivement déterminée : $23 \pm 2,2^{\circ} \mathrm{C}, 20,8 \pm 1,7^{\circ} \mathrm{C}, 14,6 \pm 3,4^{\circ} \mathrm{C}$, et $21,5 \pm$ $3,8^{\circ} \mathrm{C}$ pendant le refroidissement et $21,8 \pm 1,6^{\circ} \mathrm{C}, 22,4 \pm 2,0^{\circ} \mathrm{C}, 27,6 \pm 3,6^{\circ} \mathrm{C}$, et $23,0 \pm 2,4^{\circ} \mathrm{C}$ pendant le réchauffement. Les temps de latence du réchauffement ont été plus courts et les temps de latence de $Q_{10}$ plus faibles que les valeurs correspondantes du refroidissement $(P<0,0 \mathrm{I})$. L'oesophage et la vessie sont des points plus susceptibles aux changements de température en comparaison avec le canal auditif et la nasopharynx.

Conclusion : En aucun point d'enregistrement de la température on n'a pu prédire fidèlement un seuil électrophysiologique. Une récupération plus rapide du temps de latence pendant le réchaufferment laisse croire que l'enregistrement de la température corporelle sous-évalue les effets du réchauffement central du cerveau. Les réponses du tronc cérébral aux stimuli auditifs peuvent servir à enregistrer les effets du refroidissement et du réchauffement central du cenveau pendant la circulation extracorporelle chez des enfants.

From the Departments of Surgery* and Anesthesiology, $\dagger$ University of Louisville and Kosair Children's Hospital, Louisville, KY, 40202

USA. ¥ Present address: Division of Cardiovascular Surgery, Children’s Hospital of Eastern Ontario, Ottawa, Ontario, Canada. Address correspondence to: Dr. Rosendo A. Rodriguez, Division of Cardiovascular Surgery, Children's Hospital of Eastern Ontario, 401 Smyth Road, Ottawa, Ontario, K1H 8Ll Canada. Phone: 613-738-3990; Fax: 613-738-4835; E-mail: Rodriguez@CHEO.ON.CA. RAR was a Cadwell Laboratories Clinical Fellow and partially supported by the Alliant Community Trust. Monitors and accesories were provided by Cadwell Laboratories (USA)

Accepted for Publication June 10, 1999 
YPOTHERMIA is critical to adequate brain protection in children undergoing total circulatory arrest (TCA) or lowflow procedures. ${ }^{1}$ During active body temperature changes, the non-cerebral sites of temperature monitoring have been found susceptible to thermal variations. ${ }^{2,3}$ Consequently, inaccurate interpretations may result when these temperature measurements are used as an approximation of the brain temperature. ${ }^{4} \mathrm{~A}$ reliable and non- invasive indicator of the cerebral effects of temperature is, therefore, useful in determining the optimal temperature for brain protection during cardiopulmonary bypass (CPB).

Auditory brainstem evoked responses (ABRs) represent the electrical activation of the subcortical auditory pathway within the first $10 \mathrm{msec}$ following an acoustic stimulus. ${ }^{5}$ Their late components, waves III and $\mathrm{V}$, generated by the neural activity between the cochlear nucleus and the inferior colliculus ${ }^{6}$ are sensitive to temperature changes in both children and adults. ${ }^{7-10}$ Consequently, rather than measuring body temperature, $\mathrm{ABRs}$ may reflect more consistently the effects of temperature on the core-brain in children.

The objective of this study was threefold. The first purpose was to evaluate the effects of temperature changes on the latency and amplitude of ABRs in a group of infants undergoing hypothermic CPB and TCA. The second goal was to determine the lowest temperature at which an identifiable ABR was detected during cooling and rewarming (the threshold). Third, ABRs were used to assess the variability of several non-cerebral sites of temperature monitoring currently used during pediatric cardiac surgery.

\section{Methods}

After approval by the Human Studies Committee in our institution, $A B R s$ and temperature from four monitoring locations (left ear canal, nasopharynx, esophagus and bladder) were simultaneously recorded in 15 infants (ages: 2 days to 14 months) undergoing $\mathrm{CPB}$ and profoundly hypothermic TCA.

\section{Temperature monitoring}

Non-cerebral body temperatures were measured by sterile, disposable thermo-couple sensors (Mon-atherm, Mallinckrodt, St. Louis MO) as follows: in the left ear canal close to the tympanic membrane; in the nasopharynx at the level of the soft palate in contact with the posterior wall, in the esophagus at the level of clearly identifiable cardiac sounds, and in the bladder using a Foley catheter with a thermistor (Smith Industries, Irvine CA). The position of the nasopharyngeal probe was verified by laryngoscopy when nec- essary. The child's ear canal was inspected for excess cerumen at the time of positioning the probes. No hearing testing was performed prior to surgery. Since the ear canal temperature had been our primary monitoring temperature site for TCA, ABR recordings during temperature variations were primarily related to changes in this temperature.

\section{Auditory brainstem evoked responses}

During $\mathrm{CPB}$, ABRs were recorded at normothermia $\left(36.1 \pm 0.2^{\circ} \mathrm{C}\right)$ and at every 1 or $2^{\circ} \mathrm{C}$ of change in ear canal temperature from the beginning of cooling ( 35.7 $\left.\pm 0.8^{\circ} \mathrm{C}\right)$ to the lowest temperature prior to TCA $(18.2$ $\left.\pm 0.2^{\circ} \mathrm{C}\right)$; and from initial rewarming $\left(19.1 \pm 0.3^{\circ} \mathrm{C}\right)$ until return to normothermia $\left(35.8 \pm 0.4^{\circ} \mathrm{C}\right)$.

The ABRs were elicited by monaural clicks ( 100 $\mu s e c)$ of alternate polarity at intensities of $85 \mathrm{~dB} n \mathrm{nHL}$ (relative to a normal adult group) and stimulus rates of 23.1 per sec. An insert earphone (Etymotic Research, Elk Grove Village, IL) was used to deliver acoustic stimuli to the right ear. The electrical responses from $A_{1}$ and $A_{2}$ referred to $F z$ grounded to the forehead were filtered $(100-3000 \mathrm{~Hz})$ and digitized ( 8 bits, maximum sampling rate of $66 \mathrm{KHz}$ per channel) by a Quantum 84 Clinical Averager (Cadwell Laboratories, Kennewick, WA). A $20 \mathrm{msec}$ analysistime was used and the number of averaged samples for each recording (800-1500 samples) was adjusted to the 1 or $2^{\circ} \mathrm{C}$ change in ear canal temperature. The final temperature at the end of each ABR recording was documented and traces were stored on disk for off-line analyses. The lowest temperatures with an identifiable wave III during cooling and rewarming were considered as their respective ABR thresholds. No wave III or V was detected between the time cooling was completed and rewarming began.

\section{Anesthetic management}

Since previous reports have found no major effects of barbiturates, ${ }^{5,11}$ narcotics, ${ }^{12}$ ketamine ${ }^{11}$ or benzodiazepines $^{5,11}$ on the ABR waveforms, anesthetic management was planned as follows: premedication consisted of midazolam $i p$, and patient \# 8 received ketamine and midazolam po as well. Additional anesthetic management consisted of loading with highdose, $100-200 \mu \mathrm{g} \cdot \mathrm{kg}^{-1}$ fentanyl and $0.1-0.2 \mathrm{mg} \cdot \mathrm{kg}^{-1}$ midazolam $i v$. Anesthesia was maintained with a constant infusion of $10 \mu \mathrm{g} \cdot \mathrm{kg}^{-1} \cdot \mathrm{hr}^{-1}$ fentanyl and 50 $\mu \mathrm{g} \cdot \mathrm{kg}^{-1} \cdot \mathrm{hr}^{-1}$ midazolam, except during the period of TCA. Pancuronium and/or vecuronium were used as required for neuromuscular blockade. No volatile anesthetic agents were used. 
TABLE I Ages, weights and cardiopulmonary bypass parameters

\begin{tabular}{|c|c|c|c|c|c|c|}
\hline \multirow[t]{2}{*}{ Case } & \multirow{2}{*}{$\begin{array}{l}\text { Age } \\
\text { (days) }\end{array}$} & \multirow{2}{*}{$\begin{array}{l}\text { Weight } \\
(\mathrm{kg})\end{array}$} & \multirow[t]{2}{*}{ Surgical procedure } & \multicolumn{3}{|c|}{ Duration (min) of } \\
\hline & & & & cooling & $T C A$ & rewarming \\
\hline 1 & 30 & 3.7 & Tetralogy of Fallot repair & 23 & 41 & 43 \\
\hline 2 & 3 & 3.7 & Arterial switch & 24 & 17 & 50 \\
\hline 3 & $14^{*}$ & 2.0 & Truncus arteriosus repair & 21 & 30 & 40 \\
\hline 4 & $180^{\star}$ & 3.4 & $P A$ and valve repair & 22 & 25 & 45 \\
\hline 5 & 7 & 3.4 & Stage I Norwood & 28 & 59 & 35 \\
\hline 6 & 52 & 3.5 & VSD and ASD repair & 20 & 36 & 35 \\
\hline 7 & 19 & 3.1 & VSD, ASD repair & 22 & 43 & 40 \\
\hline 8 & 362 & 8.9 & Hemifontan procedure & 26 & 45 & 40 \\
\hline 9 & 3 & 2.8 & Homotopic heart transplant & 24 & 22 & 35 \\
\hline 10 & 120 & 5.8 & PA reconstr, BDG & 29 & 54 & 40 \\
\hline 11 & 6 & 3.4 & Arterial switch & 30 & 15 & 30 \\
\hline 12 & 2 & 2.6 & Stage I Norwood & 32 & 61 & 40 \\
\hline 13 & 35 & 4.0 & Stage I Norwood & 26 & 56 & 48 \\
\hline 14 & 60 & 4.0 & VSD repair & 20 & 35 & 37 \\
\hline 15 & 11 & 2.5 & Truncus arteriosus repair & 20 & 49 & 40 \\
\hline
\end{tabular}

$\mathrm{ASD}=$ atrial septal defect; VSD = ventricular septal defect; PA = pulmonary artery; BDG = bidirectional Glenn shunt, PA = pulmonary artery, reconstr. $=$ reconstruction, ${ }^{*}$ indicates premature gestation $(=$ or $<36$ weeks $)$.

TABLE II Individual ABR thresholds, non-cerebral temperature sites and $\mathrm{Q}_{10}$ ratios.

\begin{tabular}{|c|c|c|c|c|c|c|c|c|c|c|}
\hline \multirow[b]{2}{*}{ Case } & \multicolumn{6}{|c|}{ Non-cerebral body temperature $\left({ }^{\circ} \mathrm{C}\right)$} & \multicolumn{2}{|c|}{ bladder } & \multicolumn{2}{|c|}{$\begin{array}{l}Q_{10} \text { wave } V \\
\text { latency ratio }\end{array}$} \\
\hline & COOL & $R E W$ & COOL & $R E W$ & COOL & $R E W$ & COOL & $R E W$ & COOL & $R E W$ \\
\hline 1 & 25.0 & 19.3 & 20.4 & 23.4 & 12.0 & 27.8 & 26.5 & 24.1 & 2.5 & 1.5 \\
\hline 2 & 21.0 & 22.5 & 20.8 & 20.4 & 20.0 & 23.7 & 21.4 & 20.0 & 2.2 & 1.6 \\
\hline 3 & 24.0 & 20.2 & 22.7 & 20.5 & 11.9 & 25.0 & 21.0 & 20.5 & 2.3 & 1.4 \\
\hline 4 & 22.0 & 24.0 & 19.0 & 24.5 & 17.0 & 28.0 & 16.0 & 28.4 & 2.1 & 2.1 \\
\hline 5 & 25.0 & 24.0 & 21.0 & 25.7 & 15.5 & 33.0 & 22.5 & 23.9 & 2.1 & 1.3 \\
\hline 6 & 23.0 & 23.5 & 21.4 & 24.0 & 10.8 & 29.0 & 19.0 & 25.0 & 2.1 & 1.4 \\
\hline 7 & 19.0 & 19.0 & 17.5 & 20.0 & 10.4 & 24.0 & 19.0 & 23.3 & 2.0 & 1.4 \\
\hline 8 & 26.0 & 22.0 & 22.0 & 22.0 & 17.6 & 28.0 & 23.0 & 23.0 & 2.6 & 1.2 \\
\hline 9 & 26.0 & 21.9 & 20.0 & 22.0 & 17.0 & 26.0 & 20.0 & 22.0 & 2.2 & 1.1 \\
\hline 10 & 24.0 & 22.7 & 22.7 & 20.4 & 8.9 & 33.9 & 14.3 & 25.4 & 2.5 & 1.3 \\
\hline 11 & 21.5 & 22.8 & 23.3 & 20.7 & 16.0 & 29.1 & 22.2 & 22.3 & 2.0 & 1.4 \\
\hline 12 & 25.0 & 22.0 & 18.5 & 26.1 & 14.1 & 29.8 & 30.1 & 20.6 & 2.4 & 1.2 \\
\hline 13 & 22.0 & 22.0 & 20.1 & 23.3 & 16.7 & 31.5 & 23.7 & 25.1 & 1.7 & 1.3 \\
\hline 14 & 20.3 & 21.0 & 20.0 & 20.5 & 17.0 & 22.4 & 21.5 & 20.0 & 1.8 & 1.4 \\
\hline 15 & 21.0 & 20.1 & 22.0 & 22.2 & 14.2 & 23.0 & 22.3 & 22.0 & 2.3 & 1.4 \\
\hline mean & 23.0 & 21.8 & 20.8 & 22.4 & $14.6^{*}$ & $27.6^{*}$ & 21.5 & 23.0 & 2.2 & $1.4 \dagger$ \\
\hline SD & 2.2 & 1.6 & 1.7 & 2.0 & 3.4 & 3.6 & 3.8 & 1.9 & 0.3 & 0.2 \\
\hline MAD & 1.9 & 1.3 & 1.3 & 1.7 & 2.7 & $2.9^{*}$ & 2.6 & 1.9 & & \\
\hline
\end{tabular}

$\mathrm{ABR}=$ Auditory brainstem evoked responses, $\mathrm{COOL}=\mathrm{Cooling}, \mathrm{REW}=$ rewarming, $\mathrm{MAD}=$ mean absolute deviations from the mean in ${ }^{\circ} \mathrm{C} ; \mathrm{SD}=$ standard deviation, $* P<0.05$ relative to ear canal temperature within the same phase of temperature variation, $\dagger P<0.05$ relative to the $Q_{10}$ wave $V$ latency ratio during cooling

\section{Method of cooling and rewarming}

Hypothermia was attained by core cooling using cooled perfusates delivered via the $\mathrm{CPB}$ machine. Temperature of the perfusate was reduced to a minimum of $4^{\circ} \mathrm{C}$ and cooling was stopped when ear canal temperature reached $18^{\circ} \mathrm{C}$. This was complimented by surface cooling using reduced air temperature on the room, a cooling blanket, and ice bags around the patient's head. Ice bags were carefully positioned to preclude contact with the nasopharyngeal or ear canal probes. The time of cooling was defined as the period from the beginning of cooling until the ear canal temperature first reached $18^{\circ} \mathrm{C}(24.5 \mathrm{~min} \pm 4 \mathrm{~min})$. No cooling time was $<20 \mathrm{~min}$ (Table I). 
Rewarming began immediately with reperfusion. Surface cooling measures were reversed and the water temperature of the heat exchanger was maintained at 5 to $10^{\circ} \mathrm{C}$ above the patient's ear canal temperature until a maximum perfusate temperature of $39^{\circ} \mathrm{C}$ was reached. The time of rewarming was calculated from initial rewarming to the time that ear canal temperature reached $35.5^{\circ} \mathrm{C}(40 \mathrm{~min} \pm 5 \mathrm{~min}$; Table I $)$.

\section{Cardiopulmonary bypass}

Extracorporeal circulation was achieved using a nonpulsatile pump flow (Sarns model 9000, Ann Arbor MI) with a membrane oxygenator (COBE VPCML plus, Arvada, $\mathrm{CO}$ ). The $\mathrm{PaCO}_{2}$ during $\mathrm{CPB}$ was maintained between 30 and $40 \mathrm{~mm} \mathrm{Hg}$ uncorrected for body temperature (i.e. alpha-stat). "Full" pump flow typically varied from 140 to $160 \mathrm{ml} \cdot \mathrm{kg}^{-1} \cdot \mathrm{min}^{-1}$ at normothermia, to $100-120 \mathrm{ml} \cdot \mathrm{kg}^{-1} \cdot \mathrm{min}^{-1}$ at moderate hypothermia $\left(27\right.$ to $28^{\circ} \mathrm{C}$ ) or $50-70 \mathrm{ml} \cdot \mathrm{kg}^{-1} \cdot \mathrm{min}^{-1}$ during profound hypothermia $\left(<22^{\circ} \mathrm{C}\right)$.

\section{Clinical evolution}

The patients were observed in the intensive care unit for seizures, prolonged unconsciousness or motor abnormalities. In case of any abnormal neurological event, this was also documented by electroencephalography (EEG).

\section{Data analysis}

Threshold identification was made visually by one of the investigators (RAR). This process was achieved by reviewing the sequence of the stored traces during both cooling and rewarming. In addition, the absolute peak latencies and peak-to-peak amplitudes for waves III and V were measured with an automatic cursor. The amplitude of wave III was calculated between its peak and the preceding negativity. Wave $\mathrm{V}$ amplitude was determined between its peak and the following maximum negativity.

Latencies and amplitudes for waves V and III were calculated at the following ear canal temperatures: $36^{\circ}$, $35^{\circ}, 33^{\circ}, 30^{\circ}, 28^{\circ}, 27^{\circ}, 26^{\circ}$ and $25^{\circ} \mathrm{C}$ during cooling and rewarming. Since wave V represents the electrical response at the level of the inferior colliculus, a $Q_{10}$ wave $V$ latency ratio was derived from these results by dividing the latency of wave $\mathrm{V}$ at ear canal temperatures of $25-26^{\circ} \mathrm{C}$ by the latency at $35-36^{\circ} \mathrm{C} . .^{13}$ This ratio indicates the magnitude of change in latency with a $10^{\circ} \mathrm{C}$ variation in a non-cerebral temperature.

\section{Statistical methods}

Values are expressed as mean \pm SD. The threshold temperature was compared across several temperature sites using one-way analysis of variance (ANOVA) with repeated measures followed by comparison of the means by the Scheffé test. The latencies and amplitudes at ear canal temperatures of $35^{\circ}, 33^{\circ}$ and $30^{\circ} \mathrm{C}$ or the $\mathrm{Q}_{10}$ latency ratios between cooling and rewarming were compared by Student $t$ tests. Pearson's correlation coefficients determined the association between two parameters. In addition to the standard deviation, variability of each monitoring temperature site at the threshold was evaluated by the mean absolute deviations (MAD) from the mean. A $P$ value $<0.05$ was considered significant.

\section{Results}

Table I shows age, weight, cooling, rewarming, CPB and TCA durations for all patients. Neurological complication was documented in three patients who showed seizures and abnormal EEG activity. Two of these infants were discharged with no seizure activity and one died four days after surgery.

Figure 1 illustrates $A B R$ latencies relative to ear canal temperatures. Figure 2 shows typical ABR recordings in a five-week old infant during active temperature changes for TCA. During hypothermia, ABR latencies increased and their amplitudes decreased. All $A B R$ waves were present at ear canal temperatures above $26^{\circ} \mathrm{C}$ (nasopharynx: $23^{\circ} \mathrm{C}$ ). A $10^{\circ} \mathrm{C}$ reduction in ear canal temperature from normothermia decreased the amplitude of waves V and III by $30 \%$ and $25 \%$ respectively. As body temperature continued to decrease and ear canal temperatures reached $23^{\circ} \mathrm{C}$, waves $V$ and III were identified in $20 \%$ and $53 \%$ of our cases respectively. The site-specific $\mathrm{ABR}$ group mean thresholds during cooling were $23.0^{\circ} \mathrm{C} \pm 2.2$ (ear canal), $20.8^{\circ} \mathrm{C} \pm 1.7$ (nasopharynx), $14.6^{\circ} \mathrm{C} \pm 3.4$ (esophagus), and $21.5^{\circ} \mathrm{C} \pm 3.8$ (bladder). One patient did not achieve electrical silence as determined by ABR until nasopharyngeal temperature reached $17.5^{\circ} \mathrm{C}$ and ear canal temperature was at $19^{\circ} \mathrm{C}$. Following reperfusion and during rewarming, the sitespecific ABR thresholds were $21.8^{\circ} \mathrm{C} \pm 1.6$ (ear canal), $22.4^{\circ} \mathrm{C} \pm 2.0$ (nasopharynx), $27.6^{\circ} \mathrm{C} \pm 3.6$ (esophagus), and $23.0^{\circ} \mathrm{C} \pm 2.4$ (bladder) (Table II). When ear canal temperatures reached $23^{\circ} \mathrm{C}$, waves III and V had been identified in $67 \%$ of our cases, but all components of the $A B R$ waveform were present in all patients when ear canal temperature reached $25^{\circ} \mathrm{C}$ (nasopharynx: $26.5^{\circ} \mathrm{C}$ ). At this stage, amplitudes of the waves V and III were comparable with $80 \%$ and $85 \%$ of their respective pre-cooling values. The largest variability of temperature monitoring at the threshold was found for the esophageal temperature followed by the bladder, ear canal and nasopharynx. 

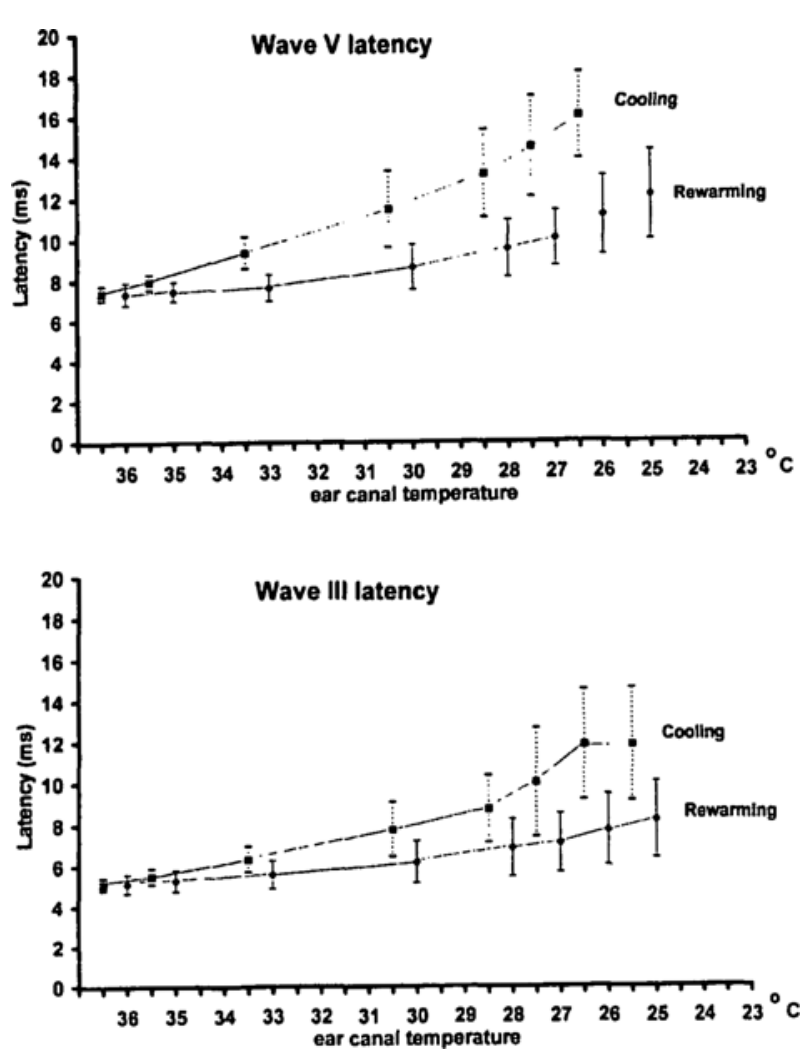

FIGURE 1 Latency changes of waves III and $V$ with variations in ear canal temperature during cooling and rewarming. Latencies doubled at temperatures of $25-26^{\circ} \mathrm{C}$ compared with initial cooling $\left(35-36^{\circ} \mathrm{C}\right)$. Latency variability was greater at lower temperatures during both cooling and rewarming. Latencies during rewarming were shorter than their respective cooling values at similar temperatures. Latency values are indicated as mean $\pm \mathrm{SD}$. The horizontal axis offset $\left(0.5^{\circ} \mathrm{C}\right)$ between "cooling" and "rewarming" was used to enhance legibility of data.

$\mathrm{ms}=$ milliseconds

The wave $V$ latencies at $35^{\circ} \mathrm{C}, 33^{\circ} \mathrm{C}$ and $30^{\circ} \mathrm{C}$ were shorter during rewarming than during cooling $(P<$ 0.01 ). Consequently, the $Q_{10}$ latency ratios were smaller during rewarming $(1.4 \pm 0.2)$ than during cooling $(2.2 \pm 0.3)(P<0.001)$. No differences were found between cooling and rewarming ABR amplitudes $(P>0.10)$. In three cases the wave $V$ latency did not return to pre-cooling values (delay: 0.1 to 0.3 msec) at the end of rewarming, but only one patient (case \# 12) showed a persistently prolonged wave $\mathrm{V}$ latency $(0.3 \mathrm{msec})$ up to the end of CPB. This patient had the longest TCA period, and, during the postoperative follow-up, clinical seizures and abnormal EEG

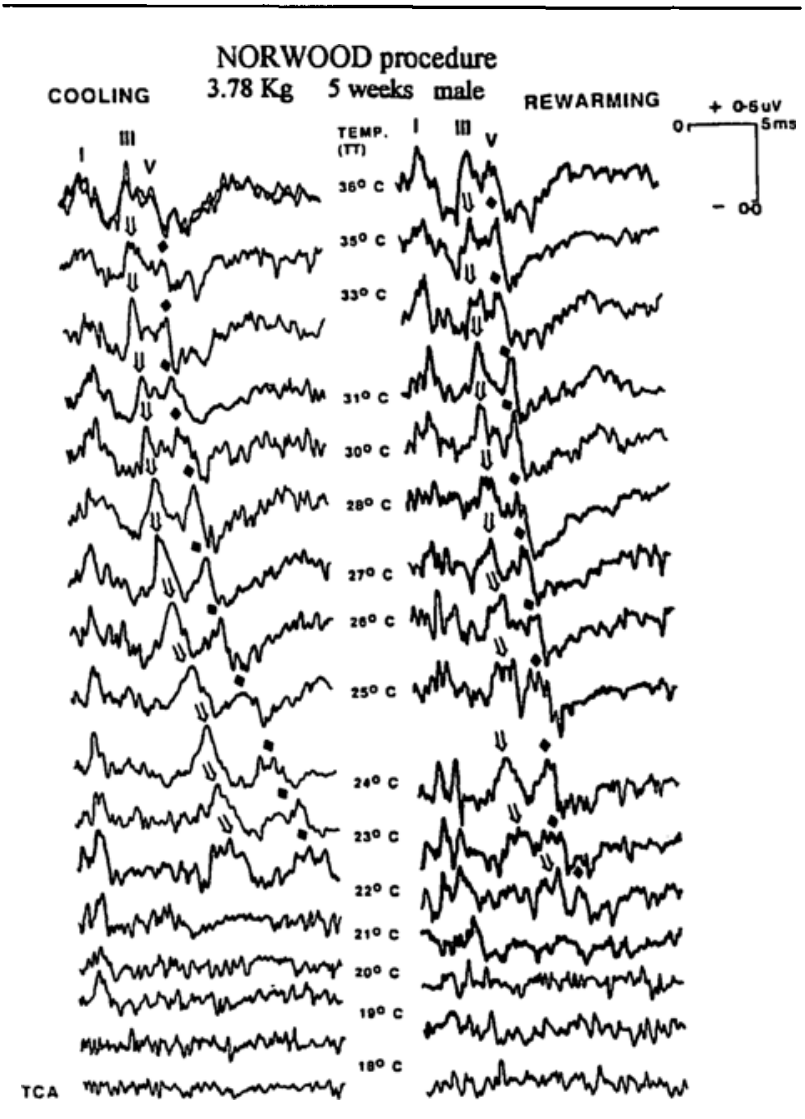

FIGURE 2 Auditory brainstem evoked responses recorded in a five-week old infant (case 13) during hypothermic cardiopulmonary bypass for total circulatory arrest (TCA). In this patient, waves $\mathrm{V}(\downarrow)$ and III $(\Downarrow)$ were reliably recorded down to ear canal temperatures of $22^{\circ} \mathrm{C}$, which was equivalent to $20.1^{\circ} \mathrm{C}, 16.7^{\circ} \mathrm{C}$ and $23.7^{\circ} \mathrm{C}$ measured respectively at the nasopharynx, esophagus and bladder. These temperatures were considered as the cooling ABR threshold. As body temperature continued to decrease, a positive deflection peaking at $2.0 \mathrm{msec}$ was the only detected evoked potential during profound hypothermia. This component disappeared under TCA. During rewarming following TCA, waves III and $\mathrm{V}$ were initially detected when ear canal temperatures reached $22^{\circ} \mathrm{C}$ or $23.3^{\circ} \mathrm{C}, 31.5^{\circ} \mathrm{C}$, and $25.1^{\circ} \mathrm{C}$ recorded respective ly in the nasopharynx, esophagus and bladder (rewarming ABR threshold). At the end of rewarming, wave $V$ latency for this patient was $0.3 \mathrm{~ms}$ shorter than its counterpart value obtained prior to cooling. $\mathrm{ms}=$ milliseconds; $\mu \mathrm{V}=$ microvoles.

$\mathrm{TCA}=$ total circulatory arrest, $\mathrm{TT}$ : ear canal temperature.

activity were detected. Although his ABR latencies during the initial rewarming were shorter than cooling values, latency delay became apparent toward the end of rewarming. The $\mathrm{ABR}$ latencies for the other two cases returned to pre-cooling values at the end of CPB and these patients did not show any adverse clinical neurological signs. No correlations were found among durations of cooling, rewarming or TCA durations and $Q_{10}$ ratios or $A B R$ threshold temperatures. 


\section{Discussion}

As in previous reports, ${ }^{7-10}$ we found that ABR latencies consistently increased and amplitudes decreased when body temperature was reduced. With increases in body temperature by rewarming, the opposite effect was observed. In our study, the lowest temperature where the subcortical auditory electrical activity was detected (wave III) differed between cooling and rewarming, depending on the site of temperature monitoring. Our findings suggest that no temperature site consistently predicts ABR thresholds in infants during active body temperature changes. The esophageal and bladder sites were more susceptible to temperature variations than were nasopharyngeal and ear canal locations. Esophageal temperature, lying in close approximation to the descending aorta, often changed rapidly with $\mathrm{CPB}$ perfusate temperature. ${ }^{4}$ Bladder temperature tended to respond more slowly, ${ }^{4}$ reflecting this being a more "vessel poor" bed than that monitored by the ear canal $^{14}$ or nasopharyngeal probes. ${ }^{2}$ This is consistent with previous reports $s^{3,4,15}$ that temperatures measured at different non-cerebral sites vary widely and may not accurately predict brain temperature. Unfortunately, even ear canal or nasopharynx temperatures failed to predict the electrical events in the brain closely, as reflected by ABRs (Table II).

Temperatures from non-cerebral locations during cooling have been found to be higher than actual brain temperatures ${ }^{2-4,15}$ but, during rewarming, temperatures commonly underestimate brain temperatures., 45 Our results showed shorter $A B R$ latencies and smaller $Q_{10}$ latency ratios during rewarming than during cooling, suggesting that both ear canal and nasopharyngeal temperatures underestimate the rewarming process of the core-brain. These findings might be important as cerebral hyperthermia may occur at the end of rewarming as a result of inaccurate measurements of core body temperature. ${ }^{16}$ Thus, ABRs may be a useful monitor during rewarming, where excessive increases in cerebral temperature enhances the susceptibility of the brain to focal ischemic insults ${ }^{17,18}$ or to the risk of a dissociated flow/metabolism ratio after TCA. ${ }^{17}$

Hypothermia decreases the brain metabolic activity and slows axonal conduction and synaptic transmission in humans and experimental animals. ${ }^{19,20}$ Human neonates ${ }^{1}$ usually show $Q_{10}$ metabolic values of 3.7 with hypothermia compared with adult values of 2.8. Our $\mathrm{Q}_{10}$ latency ratios averaged 2.2 during cooling, a lower value than expected for brain metabolic suppression induced with $10^{\circ} \mathrm{C}$ reduction in the infant's body temperature. However, our $\mathrm{Q}_{10}$ latency values in young infants, are in agreement with those reported in older children by Kaga et al. ${ }^{8}$ They suggested that their ABR latencies increased to about $200 \%$ with cooling from 36 to $26^{\circ} \mathrm{C}$ using rectal temperature monitoring.

\section{Study limitations}

There is no previous evidence indicating that the $A B R$ threshold correlates with adequate cerebral metabolic suppression prior to TCA. Also, ABRs have not been recorded in cases of excessive rewarming after hypothermic CPB. In order to become clinically applicable, further studies should address the correlation between ABRs and other indicators of brain metabolism $^{1}$ or core-brain temperature. ${ }^{4,15}$ Furthermore, the small sample size in our study precludes any association with clinical outcome. Interestingly, one patient showed unrecovered wave V latency at the end of CPB and his clinical evolution was followed by postoperative seizures. Although the importance of this finding is unknown, any persistently unrecovered wave $V$ latency at the end of rewarming should alert to the possibility of brainstem dysfunction.

The latency of all ABR components decreases in infants within the first year of life. ${ }^{5,11}$ Several factors such as myelination, cochlear maturation, resolution of middle ear abnormalities (fluid, unabsorbed mesenchyme), increased synaptic efficiency and firing synchrony may be responsible for these physiological alterations. ${ }^{5}$ Experimental evidence in animals ${ }^{13}$ suggests that the immature auditory pathway responds to the effects of cooling with a greater delay in transmitter release and prolonged ABR latencies than does a more mature system. This may indicate an age dependent sensitivity to the effects of brain cooling. In addition, since the temperature of an internal body site is influenced by the rate of blood flow through the site, ${ }^{2}$ hemodynamic alterations as a result of the underlying congenital heart disease might account for some variations in the monitoring temperature.

Previous investigations indicate that hypoxic and hypercapnic conditions which depress the electrical activity of the cerebral cortex do not depress ABRs. ${ }^{21}$ This seems to suggest that the ABR generating structures are still able to function in the presence of severe deviations from homeostasis. Although $\mathrm{ABRs}$ have been used for monitoring brainstem ischemia, ${ }^{22}$ cerebral hypoperfusion that quickly results in an isoelectric EEG, does not initially alter the ABRs ${ }^{23}$ This appears to indicate that the brainstem auditory pathway is still capable of generating its electrical response at extremely low levels of blood flow.

The brain structures involved in the generation of ABRs and their resistance to the effects of narcoticbased anesthesia, ${ }^{11,12}$ sedatives $^{11}$ or nitrous oxide /halothane anesthesia, ${ }^{5,11}$ make them useful for moni- 
toring the effects of temperature on the core-brain. This pharmacological "resistance" does not extend to enflurane, which has been shown to cause a temperature independent prolongation of the ABR latencies. ${ }^{24}$ In experimental animals, cooling temperatures of deep brain structures (e.g. hypothalamus) tend to lag behind cortical cooling by approximately $1.0^{\circ} \mathrm{C} .^{14}$ In humans, Stone et al. ${ }^{4,15}$ found temperatures $3.6^{\circ} \mathrm{C}$ higher at deep brain structures relative to the surface, which may be related to the outside brain cooling more rapidly due to the proximity of cerebral arteries. ${ }^{14}$ In addition, auditory brainstem regions have the highest levels of glucose utilization ${ }^{25}$ indicating that this neural pathway functions at higher levels of local cerebral energy metabolism. Thus, the core brain may still be physiologically active while the cortex has essentially stopped neural activity during cooling. Consequently, in addition to other electrophysiological indicators (e.g. EEG), monitoring $\mathrm{ABRs}$ may give another and potentially more conservative guide to determine if brain electrical activity has been adequately suppressed prior to TCA.

\section{Acknowledgments}

The authors greatly appreciate the cooperation of Drs. Charles Carter, Walter Rose, Rebecca Layton, Sandy Lapin, residents, nurses and perfusionists. The comments to this manuscript by Drs. Otto Teixeira and Martin C. Hosking are gratefully appreciated.

\section{References}

1 Greeley WJ, Kern FH. Cerebral blood flow and metabolism during infant cardiac surgery. Paediatr Anaesth 1994; 4: 285-99.

2 Whitby JD, Dunkin LJ. Cerebral, oesophageal and nasopharyngeal temperatures. Br J Anaesth 1971;43: 673-6.

3 Coselli JS, Crawford ES, Beall AC Jr, Mizrabi EM, Hess $K R$, Patel VM. Determination of brain temperatures for safe circulatory arrest during cardiovascular operation. Ann Thorac Surg 1988; 45: 638-42.

4 Stone JG, Young WL, Smith CR, et al. Do standard monitoring sites reflect true brain temperature when profound hypothermia is rapidly induced and reversed? Anesthesiology 1995; 82: 344-51.

5 Picton TW, Stapells DR, Campbell KB. Auditory evoked potentials from the human cochlea and brainstem. J Otolaryngol 1981; 10(Supp19): 1-41.

6 Moller $A R$, Jannetta PJ. Neural generators of the auditory brainstem response. In: Jacobson JT (Ed.). The Auditory Brainstem Response. San Diego: College-Hill Press, 1985: 13-31.
7 Markand ON, Lee BI, Warren C, et al. Effects of hypothermia on brainstem auditory evoked potentials in humans. Arn Neurol 1987; 22: 507-13.

8 Kaga K, Takigucbi T, Myokai K, Shiode A. Effects of deep hypothermia and circulatory arrest on the auditory brain stem responses. Arch Otorhinolaryngol 1979; 225: 199-205.

9 Kusakari J, Inamura $N$, Sakurai $T$, Kawamoto $K$. Effect of hypothermia upon the electrocochleogram and auditory evoked brainstem response. Tohoku J Exp Med 1984; 143: 351-9.

10 Rodriguez RA, Audenaert SM, Austin EH III, Edmonds HL $J r$. Auditory evoked responses in children during hypothermic cardiopulmonary bypass: report of cases. J Clin Neurophysiol 1995; 12: 168-76.

11 Chiappa KH. Brainstem auditory evoked potentials: methodology. In: Chiappa KH (Ed.). Evoked Potentials in Clinical Medicine. New York: Raven Press; 1983: 105-43.

12 Schwender D, Rimkus T, Haessler R, Klasing S, E. Pöppel, Peter $K$. Effects of increasing doses of alfentanil, fentanyl and morphine on mid-latency auditory evoked potentials. Br J Anaesth 1993; 71: 622-8.

13 Williston JS, Jewett $D L$. The $\mathrm{Q}_{10}$ of auditory brain stem responses in rats under hypothermia. Audiology 1982; 21: 457-65.

14 Baker MA, Stocking RA, Mecban JP. Thermal relationship between tympanic membrane and hypothalamus in conscious cat and monkey. J Appl Physiol 1972; 32: 739-42.

15 Stone $J G$, Schwartz $A E$, Finck $A D$, et al. Brain temperature monitoring during induced hypothermia. Anesthesiology 1995; 83: A173.

16 Natban HJ, Lavallée G. The management of temperature during hypothermic cardiopulmonary bypass: I Canadian survey. Can J Anaesth 1995; 42: 669-71.

17 Murkin JM. Hypothermic cardiopulmonary bypass time for a more temperate approach? (Editorial) Can J Anaesth $1995 ; 42: 663-8$.

18 Kern FH, Jonas $R A$, Mayer JE Jr, Hanley FL, Castaneda $A R$, Hickey $P R$. Temperature monitoring during CPB in infants: does it predict efficient brain cooling? Ann Thorac Surg 1992; 54: 749-54.

19 Bénita $M$, Condé $H$. Effects of local cooling upon conduction and synaptic transmission. Brain Res 1972; 36 133-51.

20 Gold S, Cabani M, Sobmer H, Horowitz M, Shahar $A$. Effects of body temperature elevation on auditory nerve-brain-stem evoked responses and EEGs in rats. Electroenceph Clin Neurophysiol 1985; 60: 146-53.

21 Sobmer $H$, Gafni $M$, Chisin $R$. Auditory nerve-brain stem potentials in man and cat under hypoxic and hypercapnic conditions. Electroenceph Clin Neurophysiol 1982; 53: 506-12. 
22 Guo J, Liao J-J, Preston JK, Batjer HH. A canine model of acute hidbrain ischemia and reperfusion. Neurosurgery $1995 ; 36$ : 986-93.

23 Sobmer H, Gafni M, Goitein K, Fainmesser P. Auditory nerve-brain stem evoked potentials in cats during manipulation of the cerebral perfusion pressure.

Electroenceph Clin Neurophysiol 1983; 55: 198-202.

24 Thornton C, Catley DM, Jordan C, Royston D, Lehane $J R$, Jones $J G$. Enflurane increases the latency of early components of the auditory evoked response in man. Br J Anaesth 1981; 53: 1102-3.

25 Sokoloff $L$, Reivich $M$, Kennedy $C$, et al. The $\left[{ }^{14} \mathrm{C}\right]$ deoxyglucose method for the measurement of local cerebral glucose utilization: theory, procedure, and normal values in the conscious and anesthetized albino rat. J Neurochem 1977; 28: 897-916. 